Gut, 1987, 28, 1569-1576

\title{
Effects of partial truncal vagotomy on intragastric pressure responses to vagal stimulation and gastric distension in ferrets
}

\author{
S A ASALA*, A J BOWER, AND I N C LAWES \\ From the Department of Anatomy and Cell Biology, University of Sheffield, Sheffield
}

SUMMARY Changes in intragastric pressure after dorsal truncal vagotomy, investigated by stimulation of the surviving vagal branches and by step inflation of the stomach, were divided into an early phase lasting five days, and a late phase continuing for at least three months. During the early phase the amplitude of vagal evoked contraction was diminished but the resting pressure and the response to gastric inflation were increased. After the fifth day vagal evoked contractions doubled in amplitude but the resting pressure and the response to step inflation of the stomach returned to control levels. Ventral vagotomy did not produce any substantial changes. Alterations to gastric and body weight, or to the relation between resting pressure and evoked contraction and relaxation were excluded as causes of the enhanced vagal effectiveness. Sprouting of axons into denervated territory occurred too late to explain the changes, but an increase in synaptic density within the innervated territory has not been ruled out.

Changes in the innervation of gastric smooth muscle after partial vagotomy merit investigation because many of the complications of vagotomy relate to alterations in motility. Selective or truncal vagotomy with drainage causes more complications related to motility than highly selective vagotomy..$^{1-1}$ Recurrence rates of ulceration after highly selective vagotomy rise considerably, however, with length of follow up ${ }^{3-5}$ which implies that there is an element of plasticity involved in secretomotor innervation. Surgery for peptic ulceration is therefore a compromise between avoiding recurrent ulceration and risking disorders of motility.

Changes in motiity after various forms of vagotomy include alteration in the rate of gastric emptying, ? reduction of phase III of cyclic motor activity ${ }^{x y}$ and irregularity of pacemaker potentials." The effects of vagotomy on motility alter with time $\mathrm{e}^{1 \mathrm{1L} \cdot 13}$ and many

Address for correspondence: I N C Lawes, Department of Anatomy, University of Sheffield, Western Bank, Sheffield S10 2TN.

Received for publication 8 May 1987.

* Present address: Dept. of Human Anatomy, Faculty of Medicine. Ahmadu Bello University, Zania, Nigeria of the effects are particularly evident in the first few postoperative months. The present investigation was designed to characterise plasticity in motor innervation, particularly with respect to which vagal trunk is involved, the time course of such changes and the possible underlying mechanisms.

The recovery of vagal evoked contractions of the ferret stomach after partial truncal vagotomy may involve changes in the target organ, increased effectiveness of the surviving extrinsic innervation, or both. Resting pressure partly determines the amplitude of vagal evoked contractions. ${ }^{1+}$ This may explain why larger stomachs are associated with greater evoked contractions ${ }^{15}$ which, in turn, may explain the correlation of body weight with the amplitude of evoked contractions. ${ }^{\text {it }}$ If vagotomy altered any of these factors then the amplitude of evoked contractions could have increased as a consequence of changes in the target organ alone, rather than in the surviving vagal branches. Thus if vagotomy caused an increase in gastric weight or an increase in resting gastric pressure, then an increase in vagal evoked contraction could be explained without recourse to neuronal plasticity. For the purposes of this paper, neuronal plasticity is defined as any longterm adap- 
tive change in a nerve which, in the present context, compensates for loss of function.

Differential loss of relaxatory influences ${ }^{15}$ and the redundancy known to exist in the vagal innervation of the stomach ${ }^{17}$ are additional potential mechanisms which have to be excluded before functional recovery can be attributed to plasticity in the vagus. A previous study ${ }^{17}$ indicated that sectioning the left cervical vagus induced an increase in responses evoked by the surviving right vagus, but not vice versa, suggesting the possibility that the left vagus is more potent than the right. Their apparent equivalence may be the result of smooth muscle limitations at suprathreshold levels of stimulation. ${ }^{1+}$ This possibility was investigated.

In the ferret, ${ }^{18-20}$ the dorsal trunk is distributed to the dorsal surface of the corpus and both surfaces of the antrum. The ventral trunk reaches only the ventral surface of the stomach, principally the corpus. The number of efferent axons is the same in the dorsal and ventral trunks and there are also equal numbers of efferents in the left and right cervical nerves. Equal numbers of neurones in the dorsal motor nuclei project to the stomach,,$^{21}$ but more in the left nucleus project to the corporoantral junction where contractions begin.

The aims of the present investigation were: (i) to determine the time course of recovery of evoked gastric contractions after partial vagotomy; (ii) to investigate any changes in the intrinsic motor responses of the stomach; (iii) to examine the possibility that changes in body weight, gastric weight, or resting intragastric pressure might contribute to the increase in vagal evoked contractions; (iv) to investigate possible changes in vagal evoked relaxation, and in particular to determine whether a selective loss of inhibition explained enhancement of contraction.

Gastric emptying and rhythmic contractions are complex phenomena which depend on a number of factors, any of which might have been altered in opposing directions by vagotomy. For this reason the less complicated contractions evoked by gastric inflation and vagal stimulation were investigated in this study.

\section{Methods}

ANIMALS

Seventy seven ferrets of either sex weighing 415-1600 $\mathrm{g}$ were used. Animals for vagotomy were anaesthetised with pentobarbitone $(60 \mathrm{mg} / \mathrm{kg}$ ip). The dorsal or the ventral abdominal trunk of the vagus was ligated below the diaphragm with two silk ligatures $1 \mathrm{~cm}$ apart. The intervening nerve was removed and later examined histologically. The abdominal wound was closed in layers and the animals were allowed to recover. The postoperative diet was water on the first day, milk on the second, and meat with fluid thereafter.

Animals were randomly allocated to one survival group, the groups being allowed to survive for 3, 5,7, 21,28 or 84 days. At the end of the survival period the animals were anaesthetised with urethane $(1.5 \mathrm{~g} / \mathrm{kg}$ $50 \% \mathrm{w} / \mathrm{v}$ in $154 \mathrm{mM}-\mathrm{NaCl}$ ip). A tracheostomy was done in all animals. The right external jugular vein was cannulated for the administration of drugs. The pylorus was occluded by a ligature. The stomach was intubated via the oesophagus with a firm plastic tube $5 \mathrm{~mm}$ external diameter, inside which was a second tube $2 \mathrm{~mm}$ external diameter. The outer tube was used to inflate the stomach rapidly with $20 \mathrm{ml}$ $154 \mathrm{mM}$-saline at $38^{\circ} \mathrm{C}$. Intragastric pressure was monitored via the inner tube connected to a pressure transducer (Bioscience model 8138), the output from which was displayed on a chart recorder (Bryans 28000).

The cervical vagi were divided and the peripheral cut ends were stimulated (Devices Isolated Stimulator timed by a Digitimer D4030) using parameters giving maximal responses $=2.2 \mathrm{~Hz}, 10 \mathrm{~s}$ trains, $0.5 \mathrm{~ms}$ pulses, voltages as in the results) delivered via bipolar silver electrodes immersed in liquid paraffin at $39^{\circ} \mathrm{C}$. Care was taken to shield the electrodes with plastic covers.

The sections of tissue removed at vagotomy were examined histologically and were shown to be neural. At the end of the experiment, the cervical vagi were stimulated after division of the surviving vagal trunk. In no case was there any evoked contraction, confirming that the previously vagotomised trunk had been totally divided as far as motor axons were concerned.

In all cases the pressure was measured with the transducer placed at the same height as the supine animals' vertebral column, or a correction was applied to give the equivalent pressure.

STATISTICAL ANALYSIS

The data were subjected to factor analysis, regression analysis, and paired (within a group of animals) or unpaired (between groups of animals) $t$ tests. Results are expressed as means $\pm S E$ of the mean.

\section{Results}

VAGAL EVOKED CONTRACTIONS

Dorsal vagotomy

Stimulation of the cervical vagi $(20 \mathrm{~V}, 10 \mathrm{~Hz}, 0.5 \mathrm{~ms}$ pulses, $10 \mathrm{~s}$ duration) caused a brief contraction of the stomach followed by a relaxation lasting several minutes.

The results of stimulating the left and/or right 
Table 1 Vagal evoked contractions after dorsal vagotomy

\begin{tabular}{lrrrrl}
\hline $\begin{array}{l}\text { Source of } \\
\text { variance }\end{array}$ & $\begin{array}{l}\text { Sumof } \\
\text { squares }\end{array}$ & df & $\begin{array}{l}\text { Mean } \\
\text { square }\end{array}$ & $F$ & $P$ \\
\hline Nerves & $38 \cdot 1$ & 2 & $19 \cdot()$ & $1 \cdot 0$ & ns \\
Days & $2213 \cdot 8$ & 6 & $369 \cdot()$ & $20 \cdot 1$ & $<() \cdot()(0)$ \\
Nerve $\times$ day & $62 \cdot 2$ & 12 & $5 \cdot 2$ & $0 \cdot 3$ & $\mathrm{~ns}$ \\
Within group & $1931 \cdot 4$ & 105 & $18 \cdot 4$ & & \\
Total & $4245 \cdot 5$ & & & & \\
\hline
\end{tabular}

Five animals per group. Nerves: left, right or both cervical evoked responses; day: postoperative survival for $0,3,5,7,21$ or 28 days; nerve $\times$ day: interaction between nerves and postoperative survival: within group: variance within each experimental group.

cervical vagi were subjected to factor analysis (Table 1), excluding the group which survived 84 days because it had only four members. Time had a highly significant effect on the amplitude of evoked response, but it did not matter which nerve was stimulated - that is, stimulation of the left, right or both cervical nerves evoked the same amplitudes of response. Because the identity of the stimulated nerve made no difference, subsequent analysis was confined to left cervical evoked responses.

Responses evoked at different intervals after vagotomy were compared with each other using an unpaired $t$ test. In the control group of six ferrets stimulation of the left cervical vagus evoked contractions of $2 \cdot 39 \pm 0 \cdot 25 \mathrm{kPa}\left(24 \cdot 4 \pm 2 \cdot 5 \mathrm{cmH}_{2} \mathrm{O}\right.$, Fig. 1). After division of the dorsal trunk (day 1 response evoked via the ventral trunk) the amplitude fell to $1 \cdot 22 \pm 0 \cdot 39 \mathrm{kPa}\left(12 \cdot 4 \pm 4 \cdot 0 \mathrm{cmH}_{2} \mathrm{O}, \mathrm{p}<0 \cdot 005\right)$, similar to the level obtained by stimulating the ventral trunk

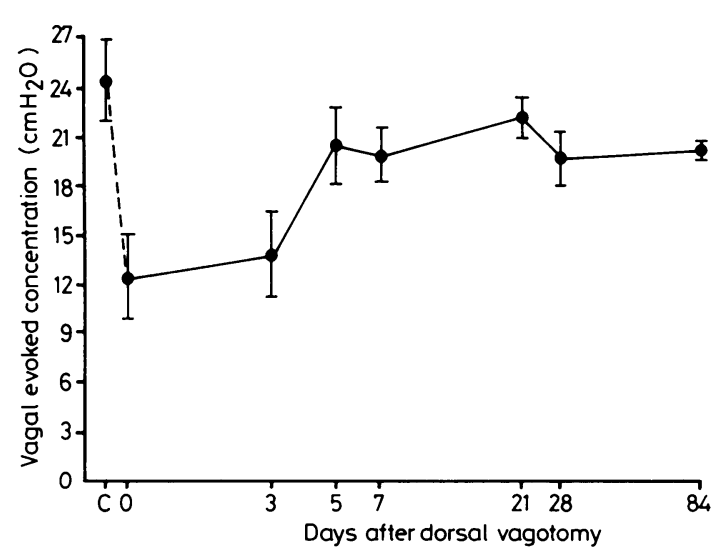

Fig. 1 Gastric contractions evoked by stimulation of the left cervical vagus after dorsal vagotomy. On the first postoperative day contractions were reduced to the amplitude of those evoked by stimulating the surviving ventral trunk. By the fifth postoperative day, however, they had increased to prevagotomy values, equal to those previously evoked by stimulating the dorsal trunk. $\left(10 \mathrm{cmH}_{2} \mathrm{O}=0.098 \mathrm{kPa}\right)$
Table 2 Vagal evoked contractions after ventral vagotomy

\begin{tabular}{lrrrrl}
\hline $\begin{array}{l}\text { Source of } \\
\text { variance }\end{array}$ & $\begin{array}{l}\text { Sumof } \\
\text { squares }\end{array}$ & df & $\begin{array}{l}\text { Mean } \\
\text { square }\end{array}$ & $F$ & $P$ \\
\hline Nerves & $6 \cdot 7$ & 2 & $3 \cdot 3$ & $0 \cdot 3$ & ns \\
Day & $181 \cdot 5$ & 5 & $36 \cdot 3$ & $3 \cdot 1$ & $<0 \cdot 05$ \\
Nerve $\times$ day & 46.2 & 10 & $4 \cdot 6$ & 0.4 & ns \\
Within group & $849 \cdot 5$ & 72 & $12 \cdot 0$ & & \\
Total & 1083.9 & & & & \\
\hline
\end{tabular}

Four animals per group. Nerves: left. right or both cervical evoked responses; day: postoperative survival for $0,3,5,7,21$ or 28 days; nerve $\times$ day: interaction between nerves and postoperative survival; within group: variance within each experimental group.

before dorsal vagotomy. The amplitude on the third day $\left(1 \cdot 35 \pm 0 \cdot 25 \mathrm{kPa}, 13.8 \pm 2 \cdot 5 \mathrm{cmH}_{2} \mathrm{O}\right)$ was lower than the control response $(\mathrm{p}<0.02)$ and was not significantly different from the day 1 response. By the fifth day, however, the amplitude $(2.01 \pm 0.23 \mathrm{kPa}$, $20 \cdot 5 \pm 2 \cdot 3 \mathrm{~cm} \mathrm{H}_{2} \mathrm{O}$ ) had returned to control levels and had increased significantly above day 1 levels $(p<0 \cdot 01)$; on all subsequent days the responses remained significantly above the day 1 levels $(p<0 \cdot 005)$. As a check to ensure that the recovery was sustained, the responses on day 84 were compared with the greatest responses (day 21) and found not to be significantly different.

Thus dorsal vagotomy halved the amplitude of the response evoked by stimulation of the cervical vagus, and the response remained low for three days. By the fifth day responses showed a substantial enhancement to prevagotomy levels, where they remained for at least three months.

\section{Ventral vagotomy}

The responses to stimulation of the left cervical vagus in control animals and at various times after ventral vagotomy are shown in Figure 2. Factor analysis (Table 2) indicated that there was no significant difference in the responses to stimulation of the left,

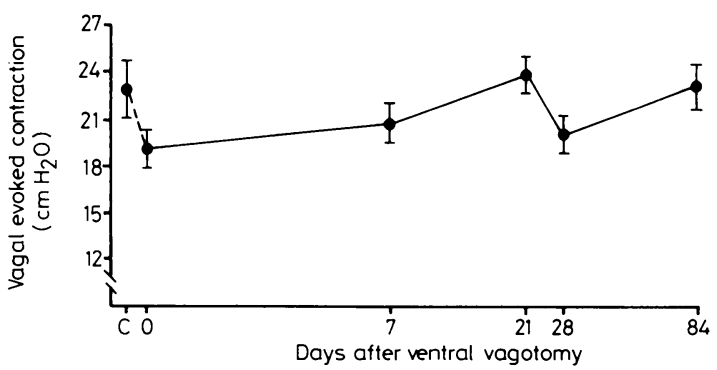

Fig. 2 Gastric contractions evoked by stimulation of the left cervical vagus after ventral truncal vagotomy. There was little change immediately after ventral vagotomy, and minimal increases above the immediate postvagotomy levels were found after 21 and 84 days. $\left(10 \mathrm{CmH}_{2} \mathrm{O}=0.098 \mathrm{kPa}\right)$ 
right or both cervical nerves. Thus the maximal contributions of the left and right cervical vagi to the dorsal trunk were equal.

The control amplitude of contraction $(2 \cdot 24 \pm 0 \cdot 19$ $\mathrm{kPa}, 22.9 \pm 1.9 \mathrm{cmH}_{2} \mathrm{O}$ ) was not significantly different from any of the amplitudes after vagotomy. The responses immediately after vagotomy (day 1 responses evoked via the dorsal trunk, $1 \cdot 87 \pm 0 \cdot 11 \mathrm{kPa}$, $19 \cdot 1 \pm 1 \cdot 1 \mathrm{cmH}_{2} \mathrm{O}$ ) were significantly lower than the responses on day $21(2.33 \pm 0.12 \mathrm{kPa}, 23.8 \pm 1.2$ $\left.\mathrm{cmH}_{2} \mathrm{O}, \mathrm{p}<0.025\right)$ and on day $84(2 \cdot 26 \pm 0.14 \mathrm{kPa}$, $\left.23 \cdot 1 \pm 1 \cdot 4 \mathrm{cmH}_{2} \mathrm{O}, \mathrm{p}<0 \cdot 05\right)$ but these differences were small and unlikely to be of great physiological importance. This shows that surgery per se, even of the ventral trunk, does not cause changes of the magnitude seen after dorsal vagotomy. Because there were no substantial changes after ventral vagotomy, the ventral groups were not examined further.

\section{Body and gastric weights}

To confirm that the allocation of ferrets to different survival groups had been randomly allocated successfully, the body weights of the ferrets which had received dorsal vagotomies were subjected to analysis of variance. Allocation to different survival times had no significant effect $(F=0.963, d f=6$ and 21 ) indicating the the groups were comparable.

Analysis of variance of the stomach weights of the animals which had received a dorsal vagotomy indicated that there was no significant difference between the groups $(\mathrm{F}=1 \cdot 669, \mathrm{df}=6$ and 21$)$.

\section{Comparison of cervical vagi}

The cervical vagi were stimulated at various intensities, from near threshold $(4 \mathrm{~V})$ to maximal levels (16 $\mathrm{V})$. The responses to stimulation of either cervical vagus were equal at 8,12 , and $16 \mathrm{~V}$. At $4 \mathrm{~V}$, however, the left vagus evoked responses $50-100 \%$ greater than those obtained from the right $(\mathrm{p}<0 \cdot 02)$.

\section{RESPONSES TO STEP INFLATION}

Responses to inflation of the stomach after division of both the cervical vagi must reflect intrinsic reflexes or myogenic contraction of the smooth muscle. Changes in either of these non-vagal mechanisms were tested collectively by giving a step inflation of the stomach. Inflation of the stomach with $20 \mathrm{ml}$ warm saline in under $2 \mathrm{~s}$ caused an immediate increase in pressure which fell to a plateau within five minutes.

The peak pressure was measured in control ferrets and at various times after dorsal vagotomy (Fig. 3). All groups had a bilateral cervical vagotomy an hour before step inflation of the stomach. After dorsal vagotomy peak pressures rose by more than $30 \%$ of the control values $\left(2 \cdot 18 \pm 0 \cdot 17 \mathrm{kPa}, 22 \cdot 2 \pm 1 \cdot 7 \mathrm{cmH}_{2} \mathrm{O}\right.$

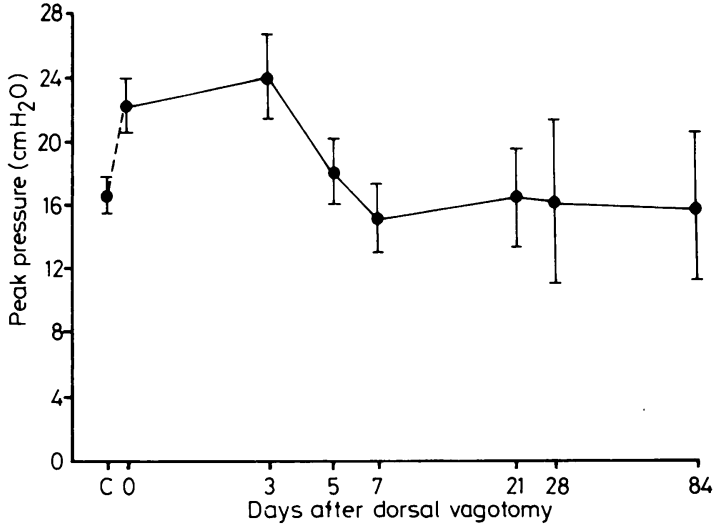

Fig. 3 Peak pressures in response to $20 \mathrm{ml}$ step inflation after dorsal vagotomy. For the first three days there was an increase in the pressure obtained, but by the fifth day the peak pressure had returned to control levels. These changes are the inverse of those affecting vagal evoked contractions (Fig. 1). $\left(10 \mathrm{cmH}_{2} \mathrm{O}=0.098 \mathrm{kPa}\right)$

v $\left.1 \cdot 63 \pm 0 \cdot 11 \mathrm{kPa}, 16 \cdot 6 \pm 1 \cdot 1 \mathrm{cmH}_{2} \mathrm{O}, \mathrm{p}<0 \cdot 01\right)$. On day 3 the peak pressures were still significantly raised $\left(2.35 \pm 0.25 \mathrm{kPa}, 24.0 \pm 2.6 \mathrm{cmH}_{2} \mathrm{O}, \mathrm{p}<0.025\right)$. By the fifth day, however, the peak pressures were no longer significantly above control levels, and on subsequent days they returned to the control values.

Enhanced contraction was temporary, therefore, disappearing at the same time (day 5) as the surviving ventral trunk became more effective.

RESTING INTRAGASTRIC PRESSURE

The resting pressure was measured 30 minutes after inflation of the stomach with $20 \mathrm{ml}$ warm saline (Fig. 4). After dorsal vagotomy the resting pressure in-

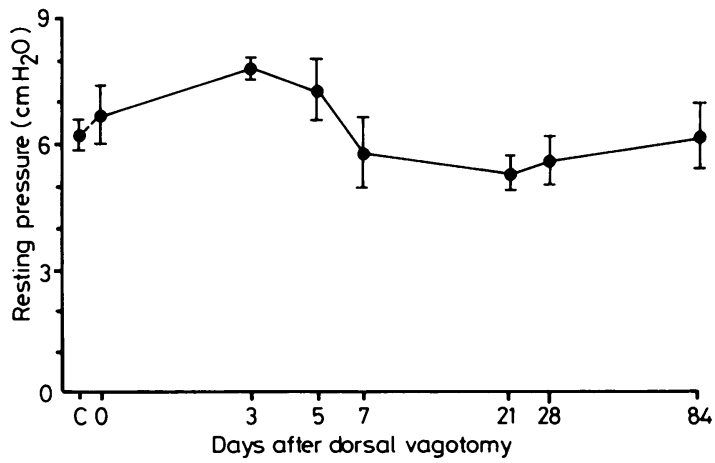

Fig. 4 Resting pressures with an intragastric volume of 20 ml after dorsal vagotomy. Resting pressure was significantly raised for the first three days after dorsal vagotomy, but it returned to control levels after five days. There was no significant reduction below control levels. $\left(10 \mathrm{cmH}_{2} \mathrm{O}=\right.$ $0.098 \mathrm{kPa}$ ) 
creased, reaching its highest level three days later $\left(0.76 \pm 0.02 \mathrm{kPa}, 7.8 \pm 0.2 \mathrm{cmH}_{2} \mathrm{O}\right)$, when it was significantly higher than control levels $(0 \cdot 61 \pm 0 \cdot 04$ $\left.\mathrm{kPa}, 6 \cdot 2 \pm 0 \cdot 4 \mathrm{cmH}_{2} \mathrm{O}, \mathrm{p}<0 \cdot 005\right)$. The resting pressure then fell, and by the fifth day it was no longer significantly raised. The pressure on day 3 was significantly higher than on day 7 and on all later days $(\mathrm{p}<0 \cdot 05)$.

Thus dorsal vagotomy had a similar effect on resting pressure as on peak pressure: the increase in resting pressures lasted only until the surviving ventral branch became more effective in evoking gastric contractions (Fig. $1 v$ Fig. 4). There was no evidence that the resting pressure fell below control levels.

\section{EVOKED CONTRACTIONS AND RESTING} PRESSURE

Within hours of vagotomy ${ }^{14}$ the regression of evoked contractions $(\mathrm{Y})$ on resting pressure $(\mathrm{X})$ was:

$$
\begin{aligned}
& \mathrm{Y}=2 \cdot 61-1.74 \times \mathrm{X}, \mathrm{n}=64, \mathrm{p}<0.001(\mathrm{kPa}) \\
& \mathrm{Y}=26.67-1.74 \times \mathrm{X}, \mathrm{n}=64, \mathrm{p}<0.001\left(\mathrm{cmH}_{2} \mathrm{O}\right)
\end{aligned}
$$

Evcked contractions in 10 of $12(83 \%)$ of the ferrets in the 0-3 day groups were less than $1.5 \mathrm{~cm} \mathrm{H}_{2} \mathrm{O}$ above the pressure predicted by this equation, whereas 21 of $28(75 \%)$ of the evoked contractions in the 5-84 day groups were more than $0 \cdot 15 \mathrm{kPa}(1 \cdot 5$ $\left.\mathrm{cmH}_{2} \mathrm{O}\right)$ above the predicted pressure $(\chi=11.697$, $\mathrm{df}=1, \mathrm{p}<0 \cdot 001)$. In short, for a given resting pressure, a greater evoked contraction was obtained after day 5 than before. This is further evidence that

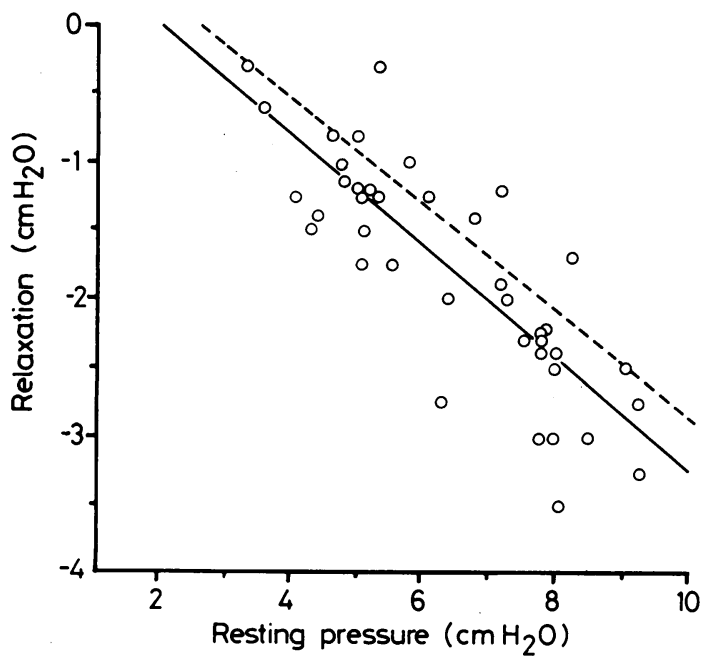

Fig. 5 Relation of vagal evoked relaxation to resting pressure more than one day after dorsal vagotomy (continuous line). For comparison the regression line obtained on the day of vagotomy is included (broken line). There is no evidence of reduced relaxation at a given pressure in the vagotomised group. $\left(10 \mathrm{~cm} \mathrm{H}_{2} \mathrm{O}=0.098 \mathrm{kPa}\right)$ changes in resting pressure did not account for the differences in evoked contractions before and after the fourth day.

\section{VAGAL EVOKED RELAXATION}

It might be postulated that an increase in vagal evoked contraction was the result of a selective loss of vagal inhibition, leaving excitatory effects unchallenged. Immediately after $10 \mathrm{~s}$ of vagal stimulation there is a contraction followed by a period of relaxation, the latter being an indication of vagally dependent inhibitory processes. ${ }^{23}$

Vagal evoked relaxation takes over $10 \mathrm{~min}$ to recover even after brief periods of stimulation, so only the first relaxatory response was analysed in each ferret. The relaxation obtained 1-84 days after dorsal vagotomy is plotted versus resting pressure in Figure 5. As the resting pressure increased the degree of relaxation also increased. The regression equation was:

$$
\begin{aligned}
& \mathrm{Y}=0.08-0.40 \times X, \mathrm{n}=40, \mathrm{p}<0.001(\mathrm{kPa}) \\
& \mathrm{Y}=0.77-0.40 \times X, \mathrm{n}=40, \mathrm{p}<0.001\left(\mathrm{cmH}_{2} \mathrm{O}\right)
\end{aligned}
$$

where $\mathrm{Y}$ is the degree of relaxation and $\mathrm{X}$ is the resting pressure. For comparison the regression line obtained from a control group (one hour after vagotomy) in a previous experiment is also shown in Figure 5. It is evident that the slopes of the two lines are very similar. The degree of relaxation obtained after dorsal vagotomy was marginally greater than in the control group.

Thus there is no evidence for a selective loss of inhibition after dorsal vagotomy nor for an alteration of the relation between vagal evoked relaxation and resting pressure.

\section{Discussion}

Two processes appear to affect vagal evoked gastric contractions after partial truncal vagotomy: an early process enhances the contraction of 'the stomach in response to a step inflation or a static intragastric volume, while a later process coming into effect as the first process wanes, enhances the effectiveness of surviving vagal branches. Enhancement of vagal evoked contractions was not explained by changes in the weights of ferrets or of their stomachs, by a decrease in resting pressure, nor by a differential loss of vagal inhibition.

EARLY CHANGES

Either an increased ability of muscle to contract or an enhanced excitability of the intrinsic reflexes were indicated by the increases in resting and inflation evoked pressure. The changes in peak (Fig. 3) and vagal evoked (Fig. 1) pressures were striking mirror images of each other, suggesting that the increased 
effectiveness of the surviving nerve might have been a signal for the disappearance of peripheral compensation, analogous to the loss of extrajunctional receptors after reinnervation of skeletal muscle..$^{2+}$ Changes in the muscle or the intrinsic reflexes did not, therefore, account for the eventual increase in effectiveness of the surviving vagal branches.

These early changes develop at the same time as the hypergastrinaemia which follows vagotomy in dogs ${ }^{25}$ and man. ${ }^{26}$ Although gastrin is known to affect the gastric pacemaker and the generation of action potentials, ${ }^{27} 28$ no link with the early changes in the present experiments has been established.

\section{LATER CHANGES}

With the exclusion of non-vagal factors and of differential loss of vagal inhibition, the increase in effectiveness of the surviving vagal branches must be caused by changes in the branches themselves or in the distribution of their activity. Possible mechanisms include neuronal sprouting, which could increase the area occupied by preganglionic neurones; increased synaptic density without change in territory; or redistribution of postganglionic neurones.

Autoradiographic studies, ${ }^{14}$ done in conjunction with the present study, showed that territorial gains by sprouting did occur, but too late (Al-Muhtaseb, personal communication) and in the wrong trunk to account for the changes in contractility recorded in the present work, although they may be related to later changes in secretion.

While sprouting into neighbouring territory was too late, an early increase in synaptic density within the original territory of the surviving branches is not excluded. Increases in synaptic density ${ }^{29}$ and the formation of functional synapses ${ }^{31-32}$ occur early enough to account for the enhanced effectiveness of the ventral vagus found on the fifth postoperative day, although there is no positive evidence of this.

An alternative explanation of the results is that after dorsal vagotomy, postganglionic neurones spread into the denervated territory, distributing activity from the ventral vagus. ${ }^{33}$

\section{FACTORS GOVERNING THE PHYSIOLOGICAL}

CHANGES

The fact that dorsal vagotomy caused a substantial increase in the effectiveness of the ventral trunk and not vice versa requires explanation, as does the previous finding ${ }^{17}$ that left, but not right, cervical vagotomy caused a similar increase.

\section{Differences between branches of the vagus}

There has been disagreement over whether the left cervical vagus has gastric effects greater than, or equal to, those of the right in dogs, cats, rabbits, ${ }^{3+}$ rats, ${ }^{35}$ cats $^{36}$ and ferrets. ${ }^{21}$ These discrepancies may be resolved by the present finding in the ferret that whereas the cervical vagi evoked equal responses at all suprathreshold levels of stimulation (when smooth muscle imposed a ceiling), at threshold levels the left cervical vagus evoked greater contractions. Those who found a greater potency of the left vagus may have been using lower intensities of stimulation. Sectioning the dorsal trunk or left cervical nerve would cause a greater loss of excitatory activity at low (presumably more physiological) intensities of stimulation than sectioning the ventral trunk or right cervical nerves. Loss of activity is a stimulus to sprouting. $30.32: 37$

The difference in the ability of the ventral and dorsal trunks to evoke gastric contractions relates to the difference in the distribution of these nerves in the ferret. ${ }^{1 \times-21}$ Nerve evoked gastric activity spreads from one part of the stomach to another only when there is a neural connection present. ${ }^{3 *}$

\section{Degeneraton as a stimulus}

Degenerating nerves induce growth of neurites in neighbouring axons. ${ }^{39-31}$.39 Degeneration of afferents, ${ }^{39}$ or loss of an inhibitory factor ${ }^{\text {t11 }}$ also induce sprouting in efferent nerves. The dorsal trunk has considerably more afferents than the ventral ${ }^{1 \times}$ and this may explain why sectioning the dorsal trunk caused a substantial increase in ventral evoked responses but not vice versa. A similar argument has been applied to left versus right cervical vagotomy in ferrets. ${ }^{17}$

\section{Functional overlap and peripheral ceilings}

In intact ferrets stimulation of the dorsal vagus gives a response as great as that obtained from stimulation of both abdominal vagi together, ${ }^{17}$ suggesting that the peripheral mechanism imposes a ceiling on the amplitude of evoked contraction ${ }^{14}$ which the normal dorsal trunk is capable of reaching independently. Thus plastic changes in the dorsal vagus after ventral vagotomy would not be expected to exceed the ceiling. The normal ventral vagus, on the other hand, cannot usually evoke a maximal contraction. Plasticity occurring in the ventral vagus, therefore, may allow this branch fuller access to the peripheral mechanism and permit visible changes in evoked contraction.

Changes in motility in the first few postoperative days after partial vagotomy involve compensatory mechanisms confined to smooth muscle or its intrinsic plexuses. By the fifth postoperative day, however, surviving branches of the vagus become more effective and the non-vagal compensatory mechanisms disappear. Sprouting of axons into neighbouring territory occurs at three months, too 
late to account for the enhanced effectiveness of the surviving vagus. An increase in synaptic density within the original territory must therefore be considered as an explanation. The extent to which these changes apply to man remains to be determined. If early changes in synaptic density do occur, then methods which prevent this ${ }^{41+2}$ may be able to contribute to the reduction of recurrent ulceration, alongside developments in surgical technique which combine the advantages of truncal and parietal cell vagotomy. ${ }^{43}$

We would like to thank P L R Andrews who made helpful comments on an earlier draft of this paper.

\section{References}

1 Donahue PE, Bombeck CT, Condon RE, Nyhus LM. Proximal gastric vagotomy versus selective vagotomy with antrectomy: results of a prospective, randomized clinical trial after four to twelve years. Surgery 1984; 96: 585-90.

2 Hoffman J, Jensen H-E, Schulze S, Poulsen PE, Christiansen J. Prospective controlled vagotomy trial for duodenal ulcer: results after five years. $\mathrm{Br} J$ Surg 1984; 74: 582-5.

3 Koffman CG, Hay DJ, Ganguli PC, et al. A prospective randomized trial of vagotomy in chronic duodenal ulceration. Four year follow up. Br J Surg 1983; 70: 342-5.

4 Stoddard CJ, Johnson AG, Duthie HL. The four to eight year results of the Sheffield trial of elective duodenal ulcer surgery - highly selective or truncal vagotomy? Br J Surg 1984; 71: 779-82.

5 Adami H-O, Enander L-K, Enshog L, Ingvar C, Rydberg B. Recurrences 1 to 10 years after highly selective vagotomy in prepyloric and duodenal ulcer disease. Ann Surg 1984; 199: 393-9.

6 Andersen D, Amdrup E, Hostrup H, Sorensen FH. The Aarhus County vagotomy trial: trends in the problem of recurrent ulcer after parietal cell vagotomy and selective gastric vagotomy with drainage. World J Surg 1982; 6: 86-92.

7 Gulsrud PO, Taylor IL, Watts HD, Cohen MB, Elashoff J, Meyer JF. How gastric emptying of carbohydrate affects glucose tolerance and symptoms after truncal vagotomy with pyloroplasty. Gastroenterology 1980; 78: 1463-71.

8 Gleysteen JL, Sarna SK, Myrvik AL. Canine cyclic motor activity of stomach and small bowel: the vagus is not the governor. Gastroenterology 1985; 88: 1926-31.

9 Mayer EA, Thomson JB, Jehn D, et al. Gastric emptying and sieving of solid food and pancreatic and biliary secretions after solid meals in patients with nonresective ulcer surgery. Gastroenterology 1984; 87: 1264-71.

10 Bortolotti M, Labo G, Serantoni C, Ciani P. Effect of highly selective vagotomy on gastric motor activity of duodenal ulcer patients. Digestion 1978; 17: 108-20.

11 Cowley DJ, Vernon P, Jones T, Glass HI, Cox AG. Gastric emptying of solid meals after truncal vagotomy and pyloroplasty in human subjects. Gut 1972; 13: 176-81.

12 Donovan IA, Clarke RJ, Gunn IF, Alexander-Williams $\mathrm{J}$. A comparison of gastric emptying at 3 and 12 months after proximal gastric or selective vagotomy without pyloroplasty. Br J Surg 1974; 61: 889-92.

13 Gleysteen JJ, Kalbfleisch JH. Progression of changes in gastric emptying of hypertonic liquids after proximal gastric vagotomy. Dig Dis Sci 1981; 26: 119-23.

14 Andrews PLR, Lawes INC. Gastric tone modifies the responses to extrinsic neural stimuli in the anaesthetised ferret. J Physiol 1985; 366: 1-16.

15 Andrews PLR, Lawes INC. The role of vagal and intramural inhibitory reflexes in the regulation of intragastric pressure in the ferret. J Physiol 1982; 326: 435-51.

16 Andrews PLR, Grundy D, Lawes INC. The role of the vagus and splanchnic nerves in the regulation of intragastric pressure in the ferret. J Physiol 1980; 307: 401-11.

17 Andrews PLR, Lawes INC, Bower AJ. Peripheral functional organisation of vagally evoked gastric motor responses in the ferret. Gut 1980; 21: 811-7.

18 Asala SA, Bower AJ. An electron microscopic study of the vagus nerve composition in the ferret. Anat Embryol 1986; 175: 247-53.

19 Asala SA, Bower AJ. Vagal innervation of the gastric wall - an autoradiographic study. J Anat 1984; 138: 589.

20 Mackay TW, Andrews PLR. A comparative study of the vagal innervation of the stomach in man and the ferret. $J$ Anat 1983; 136: 449-81.

21 Odekunle A, Bower AJ. The brainstem localization of the vagal gastric efferent neurons in the ferret; a horseradish peroxidase neurohistochemical study. $J$ Anat 1983; 138: 589.

22 Andrews PLR, Scratcherd T. The gastric motility patterns induced by direct and reflex excitation of the vagus nerves in the anaesthetized ferret. J Physiol 1980; 302: 363-78.

23 Andrews PLR, Lawes INC. Characteristics of the vagally driven non-adrenergic non-cholinergic inhibitory innervation of ferret gastric corpus. J Physiol 1985; 363: 1-20.

24 Frank E, Jansen JKS, Lomo T, Westgaard RH. The interaction between foreign and original motor nerves innervating the soleus muscle of rats. J Physiol 1975; 247: 725-43.

25 Hollinshead JW, Debas HT, Yamada T, Elashoff J, Osadachey B, Walsh JH. Hypergastrinaemia develops within 24 hours of truncal vagotomy in dogs. Gastroenterology 1985; 88: 35-40.

26 Busman DC, Munting JDK. Results of highly selective vagotomy in a non-university teaching hospital. $\mathrm{Br} J$ Surg 1982; 69: 620-4.

27 Morgan KG, Schmalz PF, Go VLW, Szursewski JH. Effect of pentagastrin, G17 and G34 on the electrical and mechanical activities of canine antral smooth muscle. Gastroenterology 1978; 75: 304-412.

28 Kelly KA. Effect of gastrin on gastric myoelectric activity. Am J Dig Dis 1970; 15: 399-405.

29 Cotman CW, Nieto-Sampedro M. Cell biology of synaptic plasticity. Science 1984; 225: 1287-94. 
30 Betz WJ, Caldwell JH, Ribchester RR. Sprouting of active nerve terminals in partially inactive muscles of the rat. J Physiol 1980; 303: 281-97.

31 Henderson CE, Hutchet M, Changeux J-P. Denervation increases a neurite-promoting activity in extracts of skeletal muscle. Nature 1983; 302: 609-11.

32 Holland RL, Brown MC. Postsynaptic transmission block can cause terminal sprouting of a motor nerve. Science 1980; 207: 649-51.

33 Brackett KA, Crocket A, Joffe SN. Sequential ultrastructural study of mucosal innervation following parietal cell vagotomy and antrectomy. Experientia 1984; 40: 850-2.

34 McCrea ED, McSwiney BA, Stopford JSB. The effect on the stomach of stimulation of the peripheral end of the vagus nerve. $Q J$ Exp Physiol 1925; 15: 201-33.

35 Lewis PR, Scott JA, Navaratnam V. Localization in the dorsal motor nucleus of the vagus in the rat. $J$ Anat 1970 ; 107: 197-208.

36 Bauer RF. Electrically induced vagal stimulation of gastric acid secretion. In: Brooks FP, Evers PW, eds. Nerves and the gut. New Jersey: CB Slack Inc, 1977, 86-95.

37 Duchen LW, Tongue DA. The effects of implantation of an extra nerve on axonal sprouting usually induced by botulinum toxin in skeletal muscle of the mouse. J Anat 1977; 124: 205-16.

38 Daniel EE, Sarna SK. Distribution of excitory vagal fibers in canine gastric wall to control motility. Gastroenterology 1976; 71: 608-613.

39 Brown MC, Ironton R. Sprouting and regression of neuromuscular synapses in partially denervated mammalian muscles. J Physiol 1978; 278: 325-48.

40 Diamond J, Cooper E, Turner C, Macintyre L. Trophic regulation of nerve sprouting. Science 1976; 193: $371-7$.

41 Schwartz M, Spearman N. Sprouting from chicken embryo dorsal root ganglia induced by nerve growth factor is specifically inhibited by affinity-purified antiganglioside antibodies. Proc Natl Acad Sci 1982; 79: 6080-3.

42 Gurney ME. Suppression of sprouting at the neuromuscular juncton by immune sera. Nature 1984; 307: 546-8.

43 Taylor TV, Gunn AA, Macleod DAD, MacLennan I. Anterior lesser curve seromyotomy and posterior truncal vagotomy in the treatment of chronic duodenal ulcer. Lancet 1982; ii: 846-9. 